This item was submitted to Loughborough's Institutional Repository (https://dspace.lboro.ac.uk/) by the author and is made available under the following Creative Commons Licence conditions.

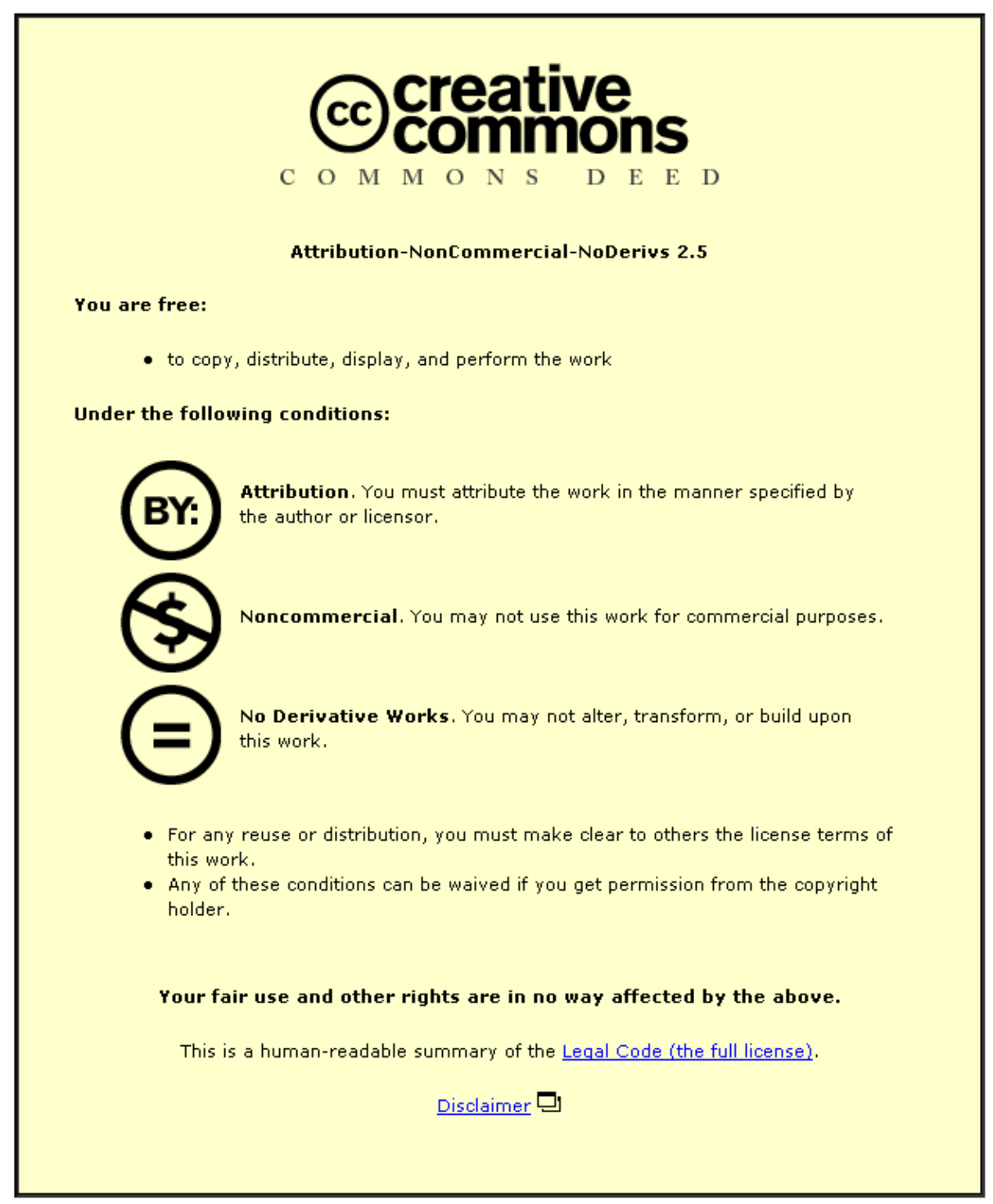

For the full text of this licence, please go to: http://creativecommons.org/licenses/by-nc-nd/2.5/ 
Waste and Resource Management Volume 165 Issue WR3

Oxo-degradable plastics: degradation, environmental impact and recycling Thomas, Clarke, McLauchlin and Patrick
Proceedings of the Institution of Civil Engineers

Waste and Resource Management 165

August 2012 Issue WR3

Pages 133-140 http://dx.doi.org/10.1680/warm.11.00014

Paper 1100014

Received 18/10/2011

Accepted 14/12/2011

Keywords: recycling \& reuse of materials/resins \& plastics/

waste management \& disposal

ICE Publishing: All rights reserved

\section{Oxo-degradable plastics: degradation, environmental impact and recycling}

Noreen L. Thomas MA, PhD, CEng, FIMMM

Senior Lecturer, Department of Materials, Loughborough University, Leicestershire, UK

Jane Clarke BSc, PhD, CChem, MRSC

Research Fellow, Department of Materials, Loughborough University, Leicestershire, UK
Andrew R. McLauchlin BSc, MPhil, PhD

Research Associate, Department of Materials, Loughborough University, Leicestershire, UK; currently Exeter University, UK

Stuart G. Patrick CSci, CChem, MRSC, FIMMM

Visiting Research Fellow, Department of Materials, Loughborough University, Leicestershire, UK

This paper summarises the results of a study to assess the environmental impact of oxo-degradable plastics. These plastics are mainly based on polyethylene and contain additives that cause the plastic to undergo oxidative degradation by a process accelerated by light and/or heat. The approach used in the study has been to review the published research on oxo-degradable plastics, assess other literature available in the public domain, and also to engage with stakeholders throughout the life cycle of the product. The main purpose of the study was to assess what happens at the end of life of the plastics and whether this has a beneficial effect. The study concluded that incorporating additives into petroleum-based plastics to accelerate their degradation does not improve their environmental impact and potentially gives rise to certain negative effects. In particular there is concern that these plastics are neither suitable for conventional recycling methods, due to the presence of degradation accelerators, nor suitable for composting, due to the lack of biodegradability. There is also concern about the fate of oxo-degradable plastic fragments in the environment.

\section{Introduction}

Oxo-degradable plastics are made of petroleum-based polymers (usually polyethylene (PE)) and contain special additives that cause them to degrade. These additives are metal salts of carboxylic acids and dithiocarbamates. The metals are typically transition metals, such as iron, nickel, cobalt and manganese (Wiles, 2005). The additives catalyse the breakdown of the long molecular chains in the plastic material and hence cause the plastic to become brittle and fragment into smaller pieces.

Oxo-degradable additives are used in plastic films in a range of products for agricultural, packaging (e.g. carrier bags) and waste disposal applications, such as refuse and composting sacks. The reason for using them is that they cause premature degradation.

Some very specific claims are made on these products, indicating that there is an environmental benefit in their use, as shown in Table 1. Such claims may give confusing messages to the public in terms of the use, re-use and disposal of this type of packaging.

This paper summarises the results of a study (Thomas et al., 2010) commissioned to assess the impact of oxo-degradable plastics on the environment. The main purpose of the project was to assess what happens at the end of life of the plastics and whether or not this has a beneficial effect compared with plastics that do not contain oxo-degradable additives.

\section{Methods and approach}

The methodology used in the study (Thomas et al., 2010) has been to review the published research in the scientific literature on oxo-degradable plastics, as well as other literature available in the public domain. Further information and views on oxo-degradable plastics were obtained by engagement with stakeholders throughout the life cycle of the product, including the additive producers, retailers, end-users and those involved in recycling and composting.

\section{Results}

The difference between oxo-degradable plastics and other petroleum-based plastics is the use of additives to give them the accelerated property of degradation. Hence the focus of this study was on the environmental effects at disposal or end of life.

\subsection{Degradation}

Evidence for degradation of oxo-degradable packaging is not difficult to come by and there is no doubt that when exposed to sunlight and/or heat for an extended period of 
'This bag is made from $100 \%$ biodegradable plastic'

'This bag is made from degradable polyethylene. It will totally degrade after 18-24 months of being buried in the ground'

'This bag is $100 \%$ degradable and recyclable'

'This bag won't be around forever. Unlike other plastic bags, which can take hundreds of years to degrade, this bag will have completely broken down in as little as one year once it reaches landfill. And without harming the environment. But before then, you can reuse it as much as you like'

Table 1. Examples of claims made on oxo-degradable plastic packaging

time, the plastic will become embrittled and fragment, as illustrated in Figure 1. Obviously, the time required depends on environmental factors, such as the intensity of solar radiation and temperature, which in turn depend on latitude and local climate.

According to the additive producers, the timescale over which these materials degrade can be tailored according to the amount of additives in the formulation. Additives include both the metal salts and the anti-oxidants added to delay the onset of degradation. However, the exact environment in which the product may end up cannot be controlled, and so specific claims as to the time and extent of degradability cannot be justified. From discussion with stakeholders, it is suggested that degradation to small plastic fragments in the UK usually takes somewhere in the range of $2-5$ years.

The mechanism of oxidative degradation of PE is widely reported in the literature (Scott, 1995; Wiles, 2005). Hydroperoxide groups are generated by means of various reactions.

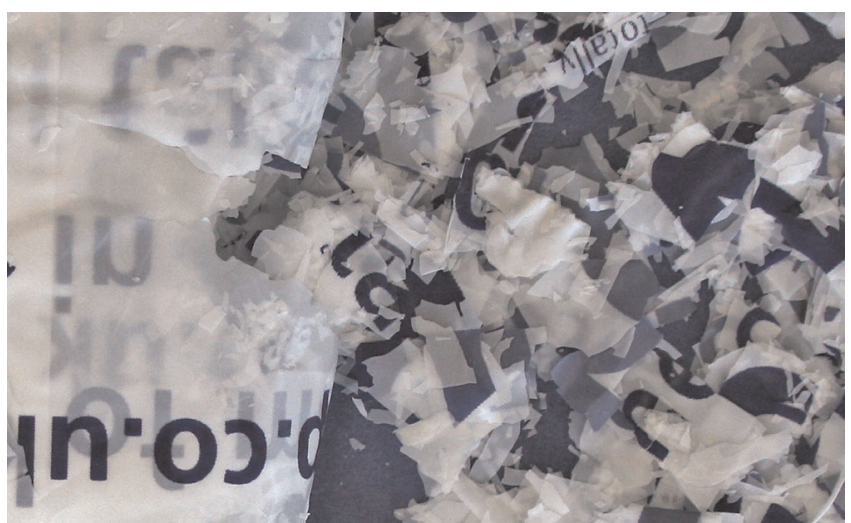

Figure 1. Illustrating degradation of an oxo-degradable carrier bag

$$
\begin{aligned}
& \mathrm{RH} \text { (heat, oxygen, stress) } \rightarrow \mathrm{ROOH} \\
& \mathrm{ROOH} \text { (heat and/or ultra-violet (UV) light) } \rightarrow \mathrm{RO} \cdot+\cdot \mathrm{OH} \\
& \mathrm{RH} \rightarrow \mathrm{R} \cdot+\mathrm{ROH}\left(\mathrm{H}_{2} \mathrm{O}\right)
\end{aligned}
$$

Decomposition of the hydroperoxide groups is catalysed by the redox reactions of the transition metal salts used as prodegradant additives, for example iron, as shown below.

$$
\begin{aligned}
& \mathrm{Fe}^{2+}+\mathrm{ROOH} \rightarrow \mathrm{Fe}^{3+}+\mathrm{RO} \cdot+\mathrm{OH}^{-} \\
& \mathrm{Fe}^{3+}+\mathrm{ROOH} \longrightarrow \mathrm{Fe}^{2+}+\mathrm{ROO} \cdot+\mathrm{H}^{+}
\end{aligned}
$$

The radicals can then react with other polymer chains to form carbonyl groups, including ketones. The carbonyl groups can then give rise to chain scission; for example, ketones can degrade as follows

$$
\mathrm{R}-\mathrm{CO}-\mathrm{R} \rightarrow \mathrm{RCOCH}_{3}+\mathrm{CH}_{2}=\mathrm{CH}-\mathrm{R}
$$

The chain scission results in the loss of mechanical properties, hence the polymer becomes brittle and will disintegrate into small fragments. In this finely fragmented form the plastic may become invisible in the environment but this does not mean that it ceases to have an impact on the environment.

\subsection{Biodegradation}

Although evidence of the degradation of oxo-degradable plastics is easy to find, it is less clear to what extent the fragments of plastic are biodegradable (i.e. capable being broken down into carbon dioxide and water by the action of bacteria and fungi).

There are many papers in the peer-reviewed literature about the 'biodegradation' of PE but the meaning of biodegradation is ill-defined. For example, some studies use the term to indicate that the PE samples were subjected to a biotic environment (soil, compost) as part of the experimental procedure (Oldak et al., 2005), whereas other studies (Karlsson et al., 1988) use the term to refer to evidence of microbial growth on the surface of the polymer. Eubeler et al. (2010) have pointed out that such microbial growth cannot be regarded as evidence of biodegradation because most microorganisms live in a biofilm, but the surface on which it forms is often not biodegraded.

There are a lot of studies investigating the chemical changes that take place in artificially weathered oxo-degradable PE, which is then incubated in soil or exposed to cultures of specific bacteria. For example, Lee et al. (1991) subjected PE containing 6\% starch to either thermal or UV light treatment and then incubated the samples with bacterial and fungal cultures. For the thermally treated samples, relative to controls without 
inoculation, some of the specimens incubated with bacteria decreased in molecular weight and elongation at break, while those incubated with fungus increased in molecular weight and elongation at break. The decrease in molecular weight is taken as evidence that biodegradation is occurring, while the relative increase in molecular weight of the specimens inoculated with fungus is attributed to a build-up of fungal organisms on the surface that inhibits oxidative degradation. There is an increase in molecular weight brought about by UV light treatment, attributed to cross-linking reactions that compete with scission reactions during photo-oxidation. Hadad et al. (2005) investigated the effect of selected bacteria on UV-treated PE with and without oxo-degradable additives, where it was the only source of carbon. They found that there was a decrease in the average molecular weight that they attributed to the action of the bacteria. They therefore concluded that the bacteria must be capable of cleaving the high molecular weight molecules - not just the lower molecular weight fragments. Reddy et al. (2009) studied changes in molecular weight distribution of a montmorillonite filled oxo-degradable $\mathrm{PE}$ after oxidation at $50-70^{\circ} \mathrm{C}$ for 14 days and subsequent incubation in a culture of $P$. aeruginosa. Incubation of the lower molecular weight material produced by thermal oxidation resulted in a decrease in average molecular weight from about 7000 to 2000 over a period of 40 days. All of these studies have used molecular weight distributions to follow the biodegradation process, but the extent of complete degradation to carbon dioxide $\left(\mathrm{CO}_{2}\right)$ cannot be measured in this way.

Conversion of the polymer to carbon dioxide is the most direct measurement of biodegradation. Narayan (2009) argues that measurement of carbon dioxide evolved when the sample is incubated in soil or compost is the true measure of biodegradability, and that it is unacceptable to claim that a plastic will 'eventually biodegrade' without stipulating the disposal environment, time period and extent of biodegradation. Therefore studies based on carbon dioxide evolution give a much more reliable indication of biodegradability than those based on, for example, weight loss measurements or images showing that the surface of the plastic has been colonised by bacteria.

An international study funded by the European Union has tested the biodegradation of an oxo-degradable PE by standard methods. This has been reported by Feuilloley et al. (2005). In this study three materials were tested: Mater-Bi (a blend of starch and a biodegradable polymer derived from petroleum); Ecoflex (a compostable synthetic polymer) and Actimais (PE with a pro-oxidant additive). These materials were tested by ten different standard ASTM, ISO and EN methods.

One of the tests used, ASTM 5988-96 (ASTM, 1996), measures the carbon dioxide evolved by the sample when incubated in real soil. In this test, the oxo-degradable PE sample showed a biodegradation of $15 \%$ after 350 days of incubation, whereas the paper control sample $\left(70 \mathrm{~g} / \mathrm{m}^{2}\right)$ showed a biodegradation of $90 \%$. Furthermore, the evolution of carbon dioxide from the oxo-degradable PE reached a maximum after 200 days and did not increase thereafter; hence a plateau was reached before 7 months. In eight of the remaining nine tests, the biodegradation of oxo-degradable PE varied from negative to a maximum of $1.8 \%$. The exception was the 'agricultural soil test' where the sample was buried in real agricultural soil for 330 days. In this test the apparent biodegradation was $90 \%$ although, as the authors commented, the assessment was made by visual inspection and it was found to be possible to extract significant quantities of microscopic fragments of PE containing pro-oxidant from the soil after the test. They also cited evidence of cross-linking between the molecular chains in the degraded PE, which may lead to fragments that can persist in the soil.

Another independent study carried out on behalf of the California integrated waste management board (CIWMB), by Rojas and Greene (2007), measured biodegradation of oxodegradable PE by the level of conversion of the material to carbon dioxide, according to ASTM D5338 (ASTM, 2003). The finding was that over 45 days, whereas the degradation of the cellulose control was greater than $70 \%$, that of the oxodegradable PE sample was $2.2 \%$, while the blank value for the compost alone was $1.7 \%$.

A number of studies by Chiellini et al. $(2003,2006,2007)$ have measured the extent to which the degraded polymer was converted by micro-organisms to carbon dioxide. In these studies the oxo-degradable plastic films are first exposed to artificial weathering conditions, either of UV light or of heat $\left(50-70^{\circ} \mathrm{C}\right)$, to accelerate the degradation process before biodegradation studies are carried out. It is not clear to what extent such accelerated weathering regimes correspond to or can be correlated with the conditions actually experienced in the environment. For this reason it is difficult to draw conclusions from these studies about the degree and timeframes for biodegradation of oxo-degradable plastics in the natural environment.

In one such study (Chiellini et al., 2007), a biodegradation of $48 \%$ after 90 days at room temperature is reported for a boiling acetone extract of thermally pretreated oxo-degradable plastic, while that for the equivalent unextracted film is about $10 \%$. Thus, the result indicates that it is the low molecular weight fractions of the degraded polymer that are biodegrading. The molecular weights of the extract quoted are in the range 1$1.7 \mathrm{kDa}$. The rate of biodegradation is thus strongly influenced by the rate and extent of reduction in molecular weight of the polymer during oxidation. 
Husarova et al. (2010) carried out biodegradation studies of unfilled and calcium carbonate filled PE containing pro-oxidant additives. Before biodegradation was measured the samples were oxidised in air at $70^{\circ} \mathrm{C}$ for 40 and 80 days. The state of oxidation and changes in molecular weight distribution tended to level out after 40 days' oxidation and this suggests that there may be a limit to the final level of oxidative degradation that can be achieved and hence a limit to the final level of biodegradation. This hypothesis is supported by the observation that levels of biodegradation were substantially similar for both the 40- and 80-day periods of pre-oxidation. Levels of biodegradation for the unfilled polymer reached $7 \%$ after 13 months in soil at $25^{\circ} \mathrm{C}$ and $23 \%$ after 8 months in compost at $58^{\circ} \mathrm{C}$.

In conclusion, it is the low molecular weight component of the oxidised oxo-degradable polymer that is capable of undergoing some biodegradation. Accelerated weathering by thermal oxidation and/or exposure to UV radiation increases the amount of low molecular weight material and hence the amount of biodegradation. However, there is difficulty in relating this artificially accelerated oxidation process to conditions in the environment where temperature, level of UV radiation and availability of oxygen are variable with location and time.

\subsection{Composting}

Oxo-degradable plastics do not pass the EN13432 (CEN, 2000) compostability standard and are therefore not claimed to be compostable. Nonetheless compostability is considered here for two reasons. First, standard composting tests are a reasonable way to compare relative biodegradation behaviour of different materials under controlled aerobic conditions. Second, the labelling of oxo-degradable plastics as biodegradable may, not unreasonably, lead consumers to dispose of them in a waste stream going to composting. In a study carried out for the CIWMB, which reports to the California Environmental Protection Agency (Rojas and Greene, 2007) oxodegradable plastics were tested in commercial composting facilities. The three composting environments were traditional windrow, in-vessel food waste and in-vessel municipal solid waste (MSW). After the composting period (of 120, 170 and 180 days respectively), the materials were recovered where possible. In all the composting facilities, compostable plastics, such as polylactic acid (PLA) and Ecoflex, had completely disintegrated. The results for the oxo-degradable bags in each environment were as follows

- City of Chico municipal compost facility: 'The oxo-degradable and UV-degradable plastics were completely intact and did not show any signs of disintegration'

- Vacaville food waste compost facility: 'The oxo-degradable plastic bags, LDPE plastic bags and
UV-degradable plastic bag did not appear to experience any degradation' (note LDPE: low-density polyethylene)

- Mariposa County MSW compost facility: 'The oxo-degradable plastic bags, LDPE plastic bags and UV-degradable plastic bag did not appear to experience any degradation'.

A similar result was experienced at a composting facility in the UK when oxo-degradable bags were used for collection of garden waste (Nichols, 2009). The resulting compost did not pass the criteria of PAS100 (BSI, 2005) and was therefore rejected for use as compost. The rejected compost and oversize bag fragments had to be consigned to landfill at considerable cost. The composting facility subsequently changed their policy to allow only certified 'compostable' bags and since then have not had any recurrence of the problem.

These examples show why the so-called 'biodegradation' of oxo-degradable plastics is of particular concern to the organics recyclers, who are in the business of making and selling compost. The presence of contamination in the form of fragments of degraded plastic will adversely affect the quality and saleability of their product. Their experience of oxo-degradables is that they do not compost in industrial composting facilities. Such companies only want materials that are compostable according to the standard EN13432 to be allowed into the composting stream.

\subsection{Bio-accumulation of plastic fragments in the environment}

An area of uncertainty is the fate of plastic fragments that remain in the soil. These are regarded as beneficial by the producers, who claim that they add to the humus content in the soil (Wiles, 2005). However, there is a lack of evidence about the environmental impact of oxo-degradable plastic fragments in the soil and a number of concerns have been raised.

It is possible that the plastic fragments may become ingested by earthworms, insects, birds or animals. Alternatively, they may enter watercourses and become ingested by fish or birds. It is also possible that they may find their way into the marine environment and become ingested by marine organisms. There is evidence that plastic debris in the marine environment can degrade to give fine particles that then become ingested and accumulate in marine organisms (Browne et al., 2008; Thompson et al., 2004).

Narayan (2009) has pointed out that oxo-degradable fragments might act to concentrate pesticide residues in the soil, as has been shown for PE and polypropylene (PP) debris found in the marine environment (Mato et al., 2001; Teuten et al., 
2007; Thompson et al., 2009). There are also concerns that degraded fragments may become cross-linked and hence persist in the environment (Feuilloley et al., 2005).

No evidence was found in this study that oxo-degradable fragments have a harmful bio-accumulative effect but neither was there evidence that they do not. It was therefore concluded that this is a topic requiring more research.

\subsection{Toxicological impact}

Research into the toxicological impact of oxo-degradable additives (Rojas and Greene, 2007) found no evidence of toxicity to tomato, cucumber or cress seeds.

Concerns have been raised about release of 'heavy metals' from the oxo-degradable additives into the soil. The additive producers respond to this by saying that the metals used are transition metals (iron, nickel, cobalt and manganese) and are not 'heavy' metals. Moreover, they are present in such small quantities that they will not significantly increase the concentrations of the metal ions already present in the soil (Scott, 2005). Their claims are supported with results from trials and calculations based on expected levels of usage. These claims seem reasonable and no evidence has been found in this study to dispute them.

\subsection{Post-consumer recycling}

According to the producers, oxo-degradables are claimed to be recyclable (i.e. capable of being recycled). This is strictly true in the sense that, even if degradation has started to take place, it is still possible to re-melt the PE and re-process it together with other recycled material. However, there is an obvious concern from plastics recyclers that the presence of oxo-degradables in the recycling stream will have an adverse effect on the quality and usability of the products made from the recycled material. It is quite clear that the product will be more prone to degradation, which will be particularly damaging for long-life applications such as membranes used in construction, and medium-life applications, such as garden furniture. The additive producers suggest that stabilisers can be added to offset the effect of the oxo-degradable additive, but the problem then arises as to the quantity of stabiliser required. Also, if the oxo-degradable plastic has already undergone degradation, this process will not be reversed by addition of stabiliser. It has been concluded on this basis that it is unreasonable to claim that oxo-degradable plastics are recyclable in existing recycling streams.

In the course of this study, it was difficult to find evidence of the impact of oxo-degradables on the recycling stream. At present there seems to be very little post-consumer recycling of the sort of plastic film products where oxo-degradable plastics are usually used. This is mainly because such material is difficult to collect, is generally of poor quality and is therefore not economically viable for recyclers. Hence, at present, any deleterious effect is limited.

There is another, more far-reaching concern. Now that this technology is being developed for use in other plastics, such as polyethylene terephthalate (PET), and for other applications, such as bottles, there is more potential for a negative impact on the quality of recycled plastic from existing recycling schemes, as discussed by the UK waste and resource action programme (WRAP, 2007).

\subsection{Littering}

Littering is an aspect about which it was difficult to acquire evidence. The oxo-degradable producers maintain that their products are a solution to the littering problem because oxo-degradable packaging will eventually degrade and then biodegrade. Some retailers are concerned that oxo-degradable carrier bags are less likely to be re-used by the public and it is much better to promote the concept of good quality multi-use carrier bags. There is also concern that oxo-degradable carrier bags may promote littering if the public are told that these bags are biodegradable.

There was not found to be any evidence that the type of carrier bag (oxo-degradable or not) affects the way in which they are disposed of by the public. The perceived amount of litter may be reduced by the use of oxo-degradables, because after embrittlement takes place the bags become fragmented and disperse. Whether this is actually beneficial or harmful for the environment depends on what happens to the plastic fragments. As discussed above, there is very little evidence for the fate of oxo-degradable fragments and this is an area identified as requiring further research. Nevertheless, as the plastics will not degrade for 2-5 years, the plastics will still cause litter within this timeframe.

\subsection{Landfill}

There is only a limited amount of information about what, if anything, happens to oxo-degradable plastics in landfill sites. Results from two reports are summarised briefly below.

A landfill study carried out by Rojas and Greene (2007) has reported that oxo-degradable PE did not undergo anaerobic biodegradation (biodegradation in the absence of air) during the study period of 43 days. A control sample of paper did biodegrade under the same anaerobic conditions to produce methane gas. This supports claims from the producers of oxodegradables that these products will not emit methane in anaerobic conditions in landfill sites. However, 43 days is a rather short time and further evidence would be required to confirm that oxo-degradable PE will not emit methane in landfill sites. 
A second landfill study was carried out on behalf of an additive manufacturer by M. J. Carter Associates (2002). This relates to aerobic conditions, that is where air is available near the surface of the landfill. There is evidence from this study that oxodegradable PE will continue to degrade in a landfill site where sufficient oxygen is available. In this study, viscosity was used as a measure of degradation because viscosity reduces as molecular weight is reduced. However, although there was an initial decrease in viscosity over the first 10 months, this was followed by an increase in viscosity over the next 3 months, with no explanation put forward for the increase in viscosity. Hence, there is some doubt about the general applicability of the findings.

\section{Conclusions and recommendations}

The overall conclusion of this study is that incorporation of additives into petroleum-based plastics that cause those plastics to undergo accelerated degradation does not improve their environmental impact and potentially gives rise to certain negative effects. Specific conclusions are listed below.

- The length of time to degradation of oxo-degradable plastic cannot be predicted accurately because it depends so much on the environmental conditions. It is suggested that oxo-degradable plastics left in the open environment in the UK degrade to small fragments in $2-5$ years.

- Biodegradation of oxo-degradable plastics can only occur after they have fragmented, and then proceeds very slowly; for example, at a rate many times slower than that of a compostable plastic.

- Oxo-degradable plastics are not compostable, according to standards EN13432 and ASTM 6400 (ASTM, 2012). Oxo-degradable plastics should not be included in waste going for composting, because the plastic fragments remaining after the composting process will adversely affect the quality and saleability of the compost.

- The fact that the term 'biodegradable' can be applied to materials with widely differing rates of biodegradation demonstrates that the term is virtually meaningless unless the rates of biodegradation and conditions under which it is measured are specified, preferably with reference to a widely recognised standard. Labelling the oxo-degradable plastics as biodegradable may lead to confusion on the part of the consumer and possible contamination of the composting waste-stream with oxo-degradable plastics. Since the term 'biodegradable' does not indicate the environment or timescale required for biodegradation to occur, it is problematic for labelling packaging. Therefore, if the term is used on packaging, the disposal environment, extent of biodegradation in a short given time period, or the time taken to complete biodegradation should be given. Alternatively, it may be better if the term 'biodegradable' is not used for labelling packaging at all, but that the label should include instructions on the best means of disposal.

- The fate of plastic fragments that remain in the soil is an area of uncertainty. Although these are regarded as beneficial by the producers, concerns have been raised that these particles of plastic may be ingested by insects, birds, animals or fish. No evidence was found in this study that oxo-degradable fragments have a harmful bio-accumulative effect, but neither was there evidence that they do not.

- No evidence of a toxicological impact of oxo-degradable additives was found in this review. It is concluded that the transition metals used are present in such small amounts that they will not significantly increase the concentrations naturally present in the soil at expected levels of usage.

- The fact that they are degradable limits the re-use of oxo-degradable bags: they are unsuitable for storing items for an extended length of time.

- Oxo-degradable plastics are not suitable for recycling with mainstream plastics. The recyclate will contain oxodegradable additives that will render the product more susceptible to degradation. Although the additive producers suggest that stabilisers can be added to protect against the oxo-degradable additives, it is problematic to determine how much stabiliser needs to be added and to what extent the oxo-degradable plastic has already degraded.

- The potential for problems to be caused by incorrect disposal of oxo-degradable plastics means that any packaging should be clearly labelled with the appropriate means of disposal. Life-cycle analysis suggests that the best means of disposal for oxo-degradable plastics is incineration with energy recovery. If incineration with energy recovery is not available then landfill is the next best option.

- The fate of oxo-degradable plastic after it has fragmented to a fine powder is not clear. Therefore it is recommended that further research is carried out to determine whether complete degradation to carbon dioxide and water is achieved, and if so, over what timescale. If the fine particles are found to persist in the environment for a long period of time, the potential for harm is such that research should be carried out to determine the effect of the particles on plants, invertebrates and animals.

- The uncertainties surrounding the effect of oxodegradable plastics on the conventional plastics recycling process means that the safest solution is to keep oxodegradable plastics out of mainstream plastics recycling processes.

\section{Acknowledgements}

This work was commissioned by the Department for the Environment, Food and Rural Affairs (Defra), UK. The 
views expressed are those of the authors and are not necessarily those of Defra. The authors are grateful to Defra for permission to publish this research, performed under contract EV0422.

\section{REFERENCES}

ASTM (1996) D5988-96: Standard test method for determining aerobic biodegradation in soil of plastic materials or residual plastic materials after composting. ASTM International, West Conshohocken, PA, USA.

ASTM (2003) D5338-98: Standard test method for determining aerobic biodegradation of plastic materials under controlled composting conditions. ASTM International, West Conshohocken, PA, USA.

ASTM (2012) D6400-12: Standard specification for labeling of plastics designed to be aerobically composted in municipal or industrial facilities. ASTM International, West Conshohocken, PA, USA.

Browne MA, Dissanayake A, Lowe DM and Thompson RC (2008) Ingested microscopic plastic translocates to the circulatory system of the mussel, Mytilus edulis. Environmental Science and Technology 2008, 42(13): 5026-5031.

BSI (2005) PAS 100:2005: Specification for composted materials. BSI, London, UK.

CEN (European Committee for Standardization (2000) EN 13432:2000 Packaging - requirements for packaging recoverable through composting and biodegradation test scheme and evaluation criteria for the final acceptance of packaging. CEN, Brussels.

Chiellini E, Corti A and Swift G (2003) Biodegradation of thermally-oxidized, fragmented low-density polyethylenes. Polymer Degradation and Stability 81(2): 341-351.

Chiellini E, Corti A, D'Antone S and Baciu R (2006) Oxobiodegradable carbon backbone polymers - oxidative degradation of polyethylene under accelerated test conditions. Polymer Degradation and Stability 91(11): 2739-2747.

Chiellini E, Corti A and D'Antone S (2007) Oxobiodegradable full carbon backbone polymers biodegradation behaviour of thermally oxidized polyethylene in an aqueous medium. Polymer Degradation and Stability 92(7): 1378-1383.

Eubeler JP, Bernhard M and Knepper TP (2010) Environmental biodegradation of synthetic polymers II. Biodegradation of different polymer groups. Trends in Analytical Chemistry 29(1): 84-100.

Feuilloley P, Guy C, Benguigui L et al. (2005) Degradation of polyethylene designed for agricultural purposes. Journal of Polymers and the Environment 13(4): 349-355.

Hadad D, Geresh S and Sivan A (2005) Biodegradation of polyethylene by the thermophilic bacterium Brevibacillus borstelensis. Journal of Applied Microbiology 98(5): 1093-1100.

Husarova L, Machovsky M, Gerych P, Houser J and Koutny M (2010) Aerobic biodegradation of calcium carbonate filled polyethylene film containing pro-oxidant additives. Polymer Degradation and Stability 95(9): 1794-1799.

Karlsson S, Ljungquist O and Albertsson A (1988) Biodegradation of polyethylene and the influence of surfactants. Polymer Degradation and Stability 21(3): 237-250.

Lee B, Pometto AL III, Fratzke A and Bailey TB Jr (1991) Biodegradation of degradable plastic polyethylene by Phanerochaete and Streptomyces species. Applied and Environmental Microbiology 57(3): 678-685.

M. J. Carter Associates (2002) Assessment of the Physical Degradation in a Landfill Environment of Plastics Manufactured with TDPA. M. J. Carter Associates, Atherstone, UK, Report No. EPI/RES/JHP/2209/01a, pp. 1-13.

Mato Y, Isobe T, Takada $\mathrm{H}$ et al. (2001) Plastic resin pellets as a transport medium for toxic chemicals in the marine environment. Environmental Science and Technology 35(2): 318-324.

Narayan R (2009) Fundamental principles and claims of biodegradability - sorting through the facts, hypes and claims of biodegradable plastics in the marketplace. Bioplastics Magazine 4(1): 28-31.

Nichols E (2009) The reality of composting biodegradable plastics. Proceedings of Conference on Bio-based and Degradable Plastics. British Plastics Federation, London, UK.

Oldak D, Kaczmarek H, Buffeteau T and Sourisseau C (2005) Photo- and bio-degradation processes in polyethylene, cellulose and their blends studied by ATRFTIR and Raman spectroscopies. Journal of Materials Science 40(16): 4189-4198.

Reddy MM, Deighton M, Bhattacharya S and Parthasarathy R (2009) Biodegradation of montmorillonite filled oxo-biodegradable polyethylene. Journal of Polymer Science 113(5): 2826-2832.

Rojas E and Greene J (2007) Performance Evaluation of Environmentally Degradable Plastic Packaging and Disposable Food Service Ware. Integrated Waste Management Board, State of California, USA, Final Report, pp. 1-70.

Scott G (1995) Introduction to the abiotic degradation of carbon chain polymers. In Degradable Polymers: Principles and Applications (Scott G and Gilead D (eds)). Chapman and Hall, London, UK, Ch. 1.

Scott G (2005) Biodegradable plastics in agriculture. In Biodegradable Polymers for Industrial Applications (Smith R (ed.)). Woodhead Publishing, Cambridge, UK, Ch. 17, pp. 451-473. 
Teuten EL, Rowland SJ, Galloway TS and Thompson RC (2007) Potential for plastics to transport hydrophobic contaminants. Environmental Science and Technology 41(22): 7759-7764.

Thomas NL, Clarke J, McLauchlin AR and Patrick SG (2010) Assessing the Environmental Impacts of Oxo-degradable Plastics Across Their Life Cycle. Department of the Environment, Food and Rural Affairs, UK, Defra Report EV0422, see http://www.fkur.com/fileadmin/ user_upload/mediainfo/heisse_eisen/loughborough_ university_oxydegradable_study.pdf (accessed 26/ 06.2012).

Thompson RC, Olsen Y, Mitchell RP et al. (2004) Lost at sea: where is all the plastic? Science 304(5672): 838.
Thompson RC, Moore CJ, vom Saal FS and Swan SH (2009) Plastics, the environment and human health: current consensus and future trends. Philosophical Transactions of the Royal Society 364(1526): 2153-2166.

Wiles DM (2005) Oxo-biodegradable polyolefins in packaging. In Biodegradable Polymers for Industrial Applications (Smith R (ed.)). Woodhead Publishing, Cambridge, UK, Ch. 3, pp. 57-76.

WRAP Research Report (2007) Consumer Attitudes to Biopolymers. Waste and Resource Action Programme (WRAP), Banbury, UK, see http://www.wrap.org.uk/ sites/files/wrap/consumer $\% 20$ attitude $\% 20$ to $\%$ 20biopolymers $\% 20$ report $\% 20$ final $\% 206$ th $\% 20$ sep $\%$ 2007.pdf (accessed 26/06.2012).

\section{WHAT DO YOU THINK?}

To discuss this paper, please email up to 500 words to the editor at journals@ice.org.uk. Your contribution will be forwarded to the author(s) for a reply and, if considered appropriate by the editorial panel, will be published as a discussion in a future issue of the journal.

Proceedings journals rely entirely on contributions sent in by civil engineering professionals, academics and students. Papers should be $2000-5000$ words long (briefing papers should be 1000-2000 words long), with adequate illustrations and references. You can submit your paper online via www.icevirtuallibrary.com/content/journals, where you will also find detailed author guidelines. 